\section{SAT0152 REAL-LIFE INFLIXIMAB AND ADALIMUMAB TROUGH LEVEL AND ANTI-DRUG ANTIBODY MEASUREMENTS IN RHEUMATOLOGY: THE FINNISH EXPERIENCE}

D. Ho ${ }^{1}$, S. Valtanen ${ }^{2}$, M. Havana ${ }^{2}$, L. Kröger ${ }^{3}$, K. Eklund ${ }^{4}$, S. Jokiranta ${ }^{1,2}$. ${ }^{1}$ Research Programs Unit, Immunobiology, University of Helsinki; ${ }^{2}$ United Medix Laboratories Ltd, Helsinki; ${ }^{3}$ Pediatric Rheumatology, Kuopio University Hospital, Kuopio; ${ }^{4}$ Rheumatology, Helsinki University and Helsinki University Hospital, Helsinki, Finland

Background: Therapeutic drug monitoring of TNF inhibitors (TNFi) may optimize clinical benefits while at the same time reducing financial costs and risk of adverse events ${ }^{1,2}$. Monitoring the TNFi trough levels (TLs) and the anti-drug antibodies (ADAbs) can provide relevant information to make rational adjustments to therapy if indicated.

Objectives: To identify distributions and trends in infliximab (IFX) and adalimumab (ADL) TLs and ADAbs from clinically requested, real-life samples from Finnish patients with rheumatoid arthritis (RA), spondyloarthropathies (SpA), or juvenile idiopathic arthritis (JIA).

Methods: Samples for TL and ADAbs were taken on a clinical basis in daily practice from four university hospitals and 15 central hospitals in Finland and sent for analysis to United Medix Laboratories. Samples were collected and analyzed from January 2012 to February 2016. TL measurements were performed by enzyme-linked immunosorbent assay (either at Sanquin laboratories, Amsterdam, The Netherlands, or in Helsinki, Finland using Promonitor ELISA, Progenika Biopharma). TLs from 2-10 $\mu \mathrm{g} / \mathrm{ml}$ (IFX) or $5-10 \mu \mathrm{g} / \mathrm{ml}$ (ADL) were considered as general target ranges. ADAb measurements were performed by radioimmunoassay (Sanquin). 1762 TL (1241 patients), 1598 ADAb (1203 patients), and 860 combined TL and ADAb samples (718 patients) were analyzed. Statistical analyses were performed by SPSS (IBM, Armonk, NY). $p<0.05$ was considered statistically significant.

Results: The highest proportions of samples with very low TLs $(<0.1 \mu \mathrm{g} / \mathrm{ml})$ were seen in IFX-treated RA patients (14.5\%) and ADL-treated SpA patients (12.6\%). The proportion of all samples in the general target range was $51.3 \%$ (IFX) and $33.4 \%$ (ADL). A greater proportion of ADL RA and SpA samples had possibly supratherapeutic $(>10 \mu \mathrm{g} / \mathrm{ml})$ TLs (RA: ADL, $22.9 \%$ vs IFX, 10.4\%, $\mathrm{p}<0.01$ and SpA: ADL, $21.4 \%$ vs IFX, $15.0 \%, p=0.05)$. A greater proportion of $A D L$ JIA samples had TLs $>10 \mu \mathrm{g} / \mathrm{ml}$ (ADL, $54.5 \%$ vs IFX, 36.3\%, $p<0.01$ ). Proportions of samples with ADAbs (>12 AU/ml) ranged from $18.0 \%$ (IFX RA) to $28.6 \%$ (ADL $\mathrm{SpA}$ ). A greater proportion of ADL samples with TLs of 2-5 $\mu \mathrm{g} / \mathrm{ml}$ and detectable ADAbs (>12 AU/ml) (RA: ADL, 3.3\% vs IFX, 0\%; SpA: ADL, 5.6\% vs IFX, 0\%; JIA: ADL, $3.4 \%$ vs IFX, $0.9 \%$ ) was observed.

Conclusions: IFX RA and ADL SpA samples had the highest proportions of very low TLs. Compared to IFX, greater proportions of ADL samples (all indications, particularly JIA) had TLs $>10 \mu \mathrm{g} / \mathrm{ml}$. Proportions of samples with ADAbs $>12$ $\mathrm{AU} / \mathrm{ml}$ ranged from $18.0 \%$ to $28.6 \%$. Compared to IFX, a greater proportion of ADL samples with possibly therapeutic TLs had detectable ADAbs.

\section{References:}

[1] Bendtzen K. Anti-TNF-alpha biotherapies: perspectives for evidence-based personalized medicine. Immunotherapy 2012;4:1167-1179.

[2] Laine J, Jokiranta TS, Eklund KK, Väkeväinen M, Puolakka K. Costeffectiveness of routine measuring of serum drug concentrations and anti-drug antibodies in treatment of rheumatoid arthritis patients with TNF- $\alpha$ blockers. Biologics 2016;10:67-73.

Disclosure of Interest: None declared

DOI: 10.1136/annrheumdis-2017-eular.5943

\section{SAT0153 EFFECTIVENESS OF LOW AND HIGH DOSE METHOTREXATE IN COMBINATION WITH ADALIMUMAB IN A REAL WORLD SETTING: RESULTS FROM THE CORRONA RHEUMATOID ARTHRITIS REGISTRY}

D. Pappas ${ }^{1,2}$, J. Griffith ${ }^{3}$, C.A. Schlacher ${ }^{3}$, Y. Shan ${ }^{2}$, C. Karki ${ }^{2}$, J.M. Kremer ${ }^{4}$ ${ }^{1}$ Columbia University, New York; ${ }^{2}$ Corrona, LLC, Southborough; ${ }^{3}$ AbbVie, Inc., Abbott Park; ${ }^{4}$ Albany School of Medicine, Albany, United States

Background: Combination therapy of methotrexate (MTX) with biologics results in superior outcomes vs. monotherapy. Recent clinical trials have shown that lower MTX doses may be sufficient in patients with rheumatoid arthritis (RA) to achieve similar clinical and patient reported outcomes (PROs) $)^{1,2}$.

Objectives: To evaluate whether high MTX dose in combination with adalimumab (ADA) results in improved clinical and PROs compared with low MTX dose.

Methods: Adult RA subjects naïve to other monoclonal antibodies, initiating standard dose ADA (40mg q2w) in combination with oral MTX (low dose: $\leq 12.5$ mgs and high dose: $\geq 15 \mathrm{mgs}$ ) during 2003-2016 and had a 6 month follow-up visit were included. The primary outcomes were mean change in clinical disease activity index (CDAl), and PROs (mHAQ, pain, fatigue, morning stiffness) from baseline to 6 months. Secondary outcomes included achievement of remission $(\mathrm{CDAl} \leq 2.8)$ /low disease activity $(\mathrm{CDAl} \leq 10)$. Outcomes were evaluated adjusting for covariates that differed at baseline using mixed model linear regression. Persistency of ADA between the two groups was examined using Kaplan-Meier survival analysis.

Results: A total of 519 patients were included: $\mathrm{N}=101$ and $\mathrm{N}=418$ initiated ADA with low and high dose MTX respectively. Patients on high dose MTX were significantly younger ( 53.3 vs 59.7 years), with lower disease duration of RA ( 8.8 vs 11.2 years) compared to low dose MTX group. Patients in the high dose group also had higher disease activity (mean CDAl: 20.8 vs 15.4 ) and more likely to be biologic-naïve $(71.3 \%$ vs $55.4 \%)$, compared to the low dose group (all $\mathrm{p}<0.05$ ). Unadjusted and adjusted analyses found no sufficient evidence that patients on high dose MTX had a better improvement in the outcomes selected (table). Persistency of ADA did not differ between the two groups.

Table: Outcomes at 6 months among ADA plus low ( $\leq 12 \mathrm{mg})$ vs. high dose ( $\geq 15 \mathrm{mg})$ combination MTX therapy

\begin{tabular}{|c|c|c|c|c|}
\hline & $\begin{array}{c}A D A+\leq 12.5 \mathrm{mg} \\
\text { (low dose) }\end{array}$ & $\begin{array}{c}A D A+\geq 15 \mathrm{mg} \\
\text { (high dose) }\end{array}$ & Unadjusted ${ }^{+}$ & Adjusted"* \\
\hline 6 month outcomes & Mean (SD) & Mean (SD) & $\beta(95 \% \mathrm{Cl})$ & $\beta(95 \% \mathrm{Cl})$ \\
\hline Change in CDAI & $-5.1(13.1)$ & $-8.0(14.2)$ & $-2.65(-5.68,0.38)$ & $2.70(0.27,5.12)$ \\
\hline Change in $\mathrm{mHAQ}$ & $-0.04(0.30)$ & $-0.09(0.43)$ & $-0.05(-0.14,0.04)$ & $0.03(-0.06,0.13)$ \\
\hline Change in pain & $-3.3(26.9)$ & $-9.0(28.1)$ & $-5.59(-11.65,0.46)$ & $2.25(-3.21,7.72)$ \\
\hline Change in fatigue & $1.8(23.3)$ & $-3(27.6)$ & $-4.81(-12.54,2.92)$ & $-1.99(-9.96,5.98)$ \\
\hline & $\begin{array}{c}\text { Response rate } \\
n(\%)\end{array}$ & $\begin{array}{c}\text { Response rate } \\
n(\%)\end{array}$ & $\begin{array}{l}\text { Odds Ratio' }(95 \% \\
\text { Cl) }\end{array}$ & $\begin{array}{c}\text { Odds Ratio"* } \\
(95 \% \mathrm{Cl})\end{array}$ \\
\hline $\begin{array}{l}\text { Achievement of } \\
\text { Remission (CDAI } 2.8 \text { ) }\end{array}$ & $7(11.7 \%)$ & $47(15.1 \%)$ & $1.17(0.47,2.88)$ & $0.92(0.36,2.4)$ \\
\hline $\begin{array}{l}\text { Achievement of LDA } \\
\text { (CDAIS10) }\end{array}$ & $28(46.7 \%)$ & $135(43.3 \%)$ & $0.841(0.47,1.49)$ & $0.63(0.31,1.26)$ \\
\hline
\end{tabular}
(Adjusted for age, duration of RA, work status, insurance status, prior biologic count, MTX continuation, basel CDAl and patient pain.

Conclusions: In this real world study, improvements in PROs and achievement of LDA/remission at 6 months were similar in the groups initiating ADA in combination with either low dose or high dose MTX.

References:

[1] Gurjit S. et al. doi:10.3899/jrheum.151009.

[2] Gerd-Rudiger Burmester. et al. doi:10.1136/annrheumdis-2013-204769.

Acknowledgements: This study is sponsored by Corrona, LLC. Corrona, LLC has been supported through contracted subscriptions in the last two years by AbbVie, Amgen, BMS, Crescendo, Eli Lilly and Company, Genentech, GSK, Horizon Pharma USA, Janssen, Momenta Pharmaceuticals, Novartis, Pfizer, Roche and UCB. The design, study conduct, and financial support for the study was provided by AbbVie. AbbVie participated in the interpretation of data, review, and approval of the abstract.

Disclosure of Interest: D. Pappas Grant/research support from: AbbVie, Inc, Consultant for: AbbVie, Inc, Employee of: Corrona, LLC, J. Griffith Shareholder of: AbbVie, Inc, Employee of: AbbVie, Inc, C. Schlacher Shareholder of: AbbVie, Inc, Employee of: AbbVie, Inc, Y. Shan Employee of: Corrona, LLC, C. Karki Employee of: Corrona, LLC, J. Kremer Shareholder of: Corrona, LLC, Grant/research support from: AbbVie, Genentech, Lilly, Novartis, Pfizer, Consultant for: AbbVie, Amgen, BMS, Genentech, Lilly, Regeneron, Sanofi, Pfizer, Employee of: Corrona, LLC DOI: 10.1136/annrheumdis-2017-eular.1525

\section{SAT0154 EFFECTIVENESS AND SAFETY OF CT-P13 IN PATIENTS WITH RHEUMATOID ARTHRITIS, ANKYLOSING SPONDYLITIS, PSORIATIC ARTHRITIS AND PLAQUE PSORIASIS: OBSERVATIONAL STUDY IN REPUBLIC OF KOREA}

D.-W. Kim ${ }^{1}$, T.-H. Kim ${ }^{2}$, S.R. Kwon ${ }^{3}$, E.Y. Lee ${ }^{4}$, C.-N. Son ${ }^{5}$, Y.S. Kim ${ }^{6}$, S.H. Kim ${ }^{7}$, Y.-B. Park ${ }^{8}$, J.-W. Hur ${ }^{9}$, H.-S. Lee ${ }^{10}$, S.J. Lee ${ }^{11}$, S.H. Lee ${ }^{11} .{ }^{1}$ Inje University Busan Paik Hospital, Busan; ${ }^{2}$ Hanyang University Hospital for Rheumatic Diseases, Seoul; ${ }^{3}$ Inha University Hospital, Incheon; ${ }^{4}$ Seoul National University College of Medicine, Seoul; ${ }^{5}$ Keimyung University Dongsan Medical Center, Daegu; ${ }^{6}$ Chosun University Hospital, Gwangiu; ${ }^{7}$ Gwangmyeong Saeum Hospital, Gyeonggi-do; ${ }^{8}$ Yonsei University Severance Hospital; ${ }^{9}$ Eulji University Seoul Hospital, Seoul; ${ }^{10}$ Hanyang University Guri Hospital, Gyeonggi-do; ${ }^{11}$ Celltrion, Inc., Incheon, Korea, Republic Of

Background: CT-P13 is approved as a biosimilar of innovator infliximab for marketing in 79 countries around the world. After approval, observational study has been conducted in Republic of Korea in patients with Rheumatoid Arthritis (RA), Ankylosing Spondylitis (AS), Psoriatic Arthritis (PsA) and Plaque Psoriasis (PS).

Objectives: To evaluate the effectiveness and safety of CT-P13 under routine care in Republic of Korea.

Methods: This observational study included both biologic naïve patients (Naïve group) and patients who switched from other anti-tumor necrosis factor (TNF)s to CT-P13 (Switch group). Effectiveness were evaluated based on remission (DAS28 $\leq 2.6$ in RA, BASDAl $<3$ in AS and absence of swollen and tender joint counts in PsA), and response (BASDAI 20/50/70 in AS and PASI 50/75 in PS). Adverse events (AEs) were collected over 6 month period.

Results: Total 940 patients (400 with RA, 531 with AS, 3 with PsA and 6 with PS) were registered and $338(36.0 \%)$ patients (108 with RA, 228 with AS, 2 with PS) who switched to CT-P13 were included.

The proportion of patients achieving remission was similar between Naïve and Switch groups in both RA and AS during post-baseline visits (Table 1). In RA, the proportion of patients achieving each disease activity category by DAS28 was similar between Naïve and Switch groups (Figure 1). The proportion of patients 